\title{
Characterizing the volatility and mixing state of ambient fine particles in the summer and winter of urban Beijing
}

\author{
Lu Chen ${ }^{1,2}$, Fang Zhang ${ }^{2}$, Don Collins ${ }^{3}$, Jingye Ren ${ }^{1}$, Jieyao Liu ${ }^{1}$, Sihui Jiang ${ }^{1}$, and Zhanqing Li $^{4}$ \\ ${ }^{1}$ College of Global Change and Earth System Science, Beijing Normal University, Beijing 100875, China \\ ${ }^{2}$ Environmental Science and Engineering Research Centre, School of Civil and Environmental Engineering, \\ Harbin Institute of Technology (Shenzhen), 518055 Shenzhen, China \\ ${ }^{3}$ Chemical and Environmental Engineering, University of California, Riverside, CA 92521, USA \\ ${ }^{4}$ Earth System Science Interdisciplinary Center and Department of Atmospheric and Oceanic Science, \\ University of Maryland, College Park, MD, USA
}

Correspondence: Fang Zhang (zhangfang2021@hit.edu.cn)

Received: 1 June 2021 - Discussion started: 5 July 2021

Revised: 24 January 2022 - Accepted: 26 January 2022 - Published: 18 February 2022

\begin{abstract}
Understanding the volatility of atmospheric aerosols is important for elucidating the formation of fine particles and to help determine their effect on the environment and climate. In this study, the volatility of fine particles $(40,80,110,150,200$, and $300 \mathrm{~nm})$ is characterized by the size-dependent volatility shrink factor (VSF) for summer and winter in the urban area of Beijing using measurements of a volatility tandem differential mobility analyzer (VTDMA). We show that there are two persistent aerosol volatility modes (one high-volatility and one less- or non-volatile mode) present both in the summer and winter. On average, the particles are more volatile in the summer (with a mean VSF of 0.3 ) than in the winter (with a mean VSF of 0.6). Although the new particle formation (NPF) process requires low-volatility vapors to form molecular clusters and nuclei, the significant high-volatility mode around noon on NPF days indicates partitioning of volatile substances into the growing particles during summer. We further retrieve the mixing state of the ambient fine particles from the size-resolved VSF and find that the non-black carbon (BC) particles that formed from nucleation processes accounted for $52 \%-69 \%$ of the total number concentration in the summer. On the other hand, particles containing a refractory core that is thought to be BC-containing particles dominate and contribute $67 \%-77 \%$ toward the total number concentration in the winter. The diurnal cycles of the retrieved aerosol mixing state for the summer further support the conclusion that the nucleation process is the main contributor to non-BC particles. In addition, the extent of aging of $\mathrm{BC}$ particles was characterized as the ratio of the $\mathrm{BC}$ diameter before and after heating at $300^{\circ} \mathrm{C}\left(D_{\mathrm{p}} / D_{\mathrm{c}}\right)$, showing that the average ratio of $\sim 2.2$ in the winter is higher than the average of $\sim 1.5$ in the summer, which indicates that $\mathrm{BC}$ aging may be less efficient in summertime. This would result in differences in light absorption enhancement between the cold and warm seasons.
\end{abstract}

1

The volatility of atmospheric aerosols affects their effect on climate, visibility, and human health (Dzubay et al., 1982; Pöschl, 2005; Baklanov et al., 2016) by modulating mass concentrations and size distributions of aerosol particles via gas-particle partitioning. Aerosol measurement could be largely biased under different temperatures because of volatility (Meyer et al., 2000; Grieshop et al., 2006; Chen et al., 2010). In addition, volatility influences the partitioning of aerosols in gas and particle phases and thus affects dry and wet deposition rates (Bidleman, 1988), chemical reaction mechanisms, and atmospheric lifetime (Huffman et al., 2009; Glasius and Goldstein, 2016). Therefore, it is important to study the volatility of aerosols in different regions and environments, including in polluted urban areas. 
Laboratory and field measurements have shown that aerosol volatility is correlated with the chemical composition of particles, which is impacted by emission sources and atmospheric processes (Wehner et al., 2004; Yeung et al., 2014). Therefore, the volatility of fine particles varies greatly with time and location. A common measure of volatility is the shrink factor (VSF), which is defined as the ratio of the particle diameter after and before being heated and is measured by a volatility tandem differential mobility analyzer (VTDMA). The VSF can range from as low as 0 (completely volatile compounds) to 1 (indicating completely non-volatile substances, e.g., black carbon), reflecting heterogeneity in particle composition in diverse environments (Y. Wang et al., 2017; Chen et al., 2020). In addition, the dependence of particle volatility on particle size is complex. For example, Y. Wang et al. (2017) found that ambient aerosol volatility typically decreases as particle size increases in urban Beijing, whereas Levy et al. (2014) showed the opposite dependence on size near the California-Mexico border. Numerous studies have linked aerosol volatility to the presence and abundance of refractory carbonaceous compounds by inferring aerosol mixing state and the degree of aging from measured volatility (Wehner et al., 2009; Cheung et al., 2016; Y. Zhang et al., 2016, 2017; Chen et al., 2020). Mixing state has been found to vary significantly between clean and heavily polluted days (Wehner et al., 2009), with a corresponding decrease in the fraction of externally mixed black carbon (BC) particles from $37 \%$ during clean to $18 \%$ during heavily polluted periods. Cai et al. (2017) showed that nearly all particles volatilized at about $300^{\circ}$ in Okinawa, while $15 \%-21 \%$ did not in Pearl River Delta. Saha et al. (2018) found the non-volatile fraction in roadside aerosols was mostly externally mixed. The results from these studies show that the aerosol mixing state and degree of aging may differ greatly under diverse ambient conditions. Considering current uncertainties in assessing the radiative forcing of $\mathrm{BC}$ particles, which are largely due to uncertainties in the model treatment of BC mixing state, emissions, and removal processes (Cappa et al., 2012; Nordmann et al., 2014), an improved understanding of aerosol volatility and mixing state is hence needed.

Most previous studies in north China have focused on aerosol chemistry, sources, and transport (Wang et al., 2010; Gao et al., 2011; Sun et al., 2016b), but few have linked the volatility and mixing state of the aerosol to its sources, formation, and growth. In north China, severe haze usually occurs in the winter season, with extremely high $\mathrm{PM}_{2.5}$, while in the summer, it occurs much less frequently and with much lower $\mathrm{PM}_{2.5}$, with the contrast resulting from influences of multiple factors such as regional and local emissions, particle formation, meteorology, and photochemistry. A comprehensive study on investigating the aerosols' volatility and mixing state in cold and warm seasons may help to elucidate the sources and chemical composition of aerosol particles.

In this study, the VTDMA system, which has been extensively employed in field observations (Sakurai et al., 2003;
Wehner et al., 2009; Cheung et al., 2016; Y. Wang et al., 2017), was used to measure size-resolved volatility at different heating temperatures during wintertime and summertime in Beijing. At the maximum employed heating temperature of $300^{\circ}$, volatile components tend to evaporate while leaving refractory materials such as BC and other non-volatile components (Cheng et al., 2009). Therefore, the VTDMA is also used to determine the mixing state of refractory carbonaceous particles (Wehner et al., 2009; Y. Zhang et al., 2016; Chen et al., 2020). Here, we used the size-dependent VSF as a parameter to characterize the volatility behavior of fine particles in cold and warm seasons of urban Beijing. In addition, the mixing state of ambient fine particles in the summer, which is retrieved from the size-resolved VSF, is also compared to that in the winter. By contrasting the volatility and mixing state in the two seasons, this study has the aim of linking the aerosol particles' volatile properties and mixing state to their atmospheric chemical and physical processes under different ambient conditions in polluted urban areas.

\section{Materials and methods}

\subsection{Sampling site}

We conducted two field campaigns from 28 January to 22 February 2019 and 15 July to 7 August 2019 at a site (Nanjiao; $39.81^{\circ} \mathrm{N}, 116.48^{\circ} \mathrm{E}$ ) located southeast of urban Beijing. The sampling site is a basic meteorological observation station of the China Meteorological Administration (CMA), which hosts the most comprehensive meteorological observation instruments of all the CMA sites (Fig. 1). The main instruments used in this study were all placed there, which were set up and deployed in a container for measuring the physicochemical properties of aerosol particles simultaneously. The fifth-ring beltway is nearby the sampling site, with no major industrial pollution sources nearby.

\subsection{Instruments and measurements}

The volatility and mixing state of fine particles were measured with a VTDMA (Fig. S1 in the Supplement). Y. Wang et al. (2017) provided a brief description of the custom-made VTDMA system. Here, we give more details. The instrument mainly consists of the following seven parts: a neutralizer, a first differential mobility analyzer $\left(\mathrm{DMA}_{1}\right)$, a temperature control module, a second DMA (DMA 2 ), a water-based condensation particle counter (WCPC, TSI model 3787), auxiliary components (electric steering valve, vacuum pump, and proportional valve, etc.), and software for control and data acquisition. During the measurement, ambient aerosols were first sampled by a $\mathrm{PM}_{2.5}$ inlet and subsequently passed through a Nafion dryer that reduced the sample flow relative humidity $(\mathrm{RH})$ to below $30 \%$. The dried aerosols were then directed through a neutralizer to neutralize the charge carried by the particles and entered the $\mathrm{DMA}_{1}$ to produce quasi- 


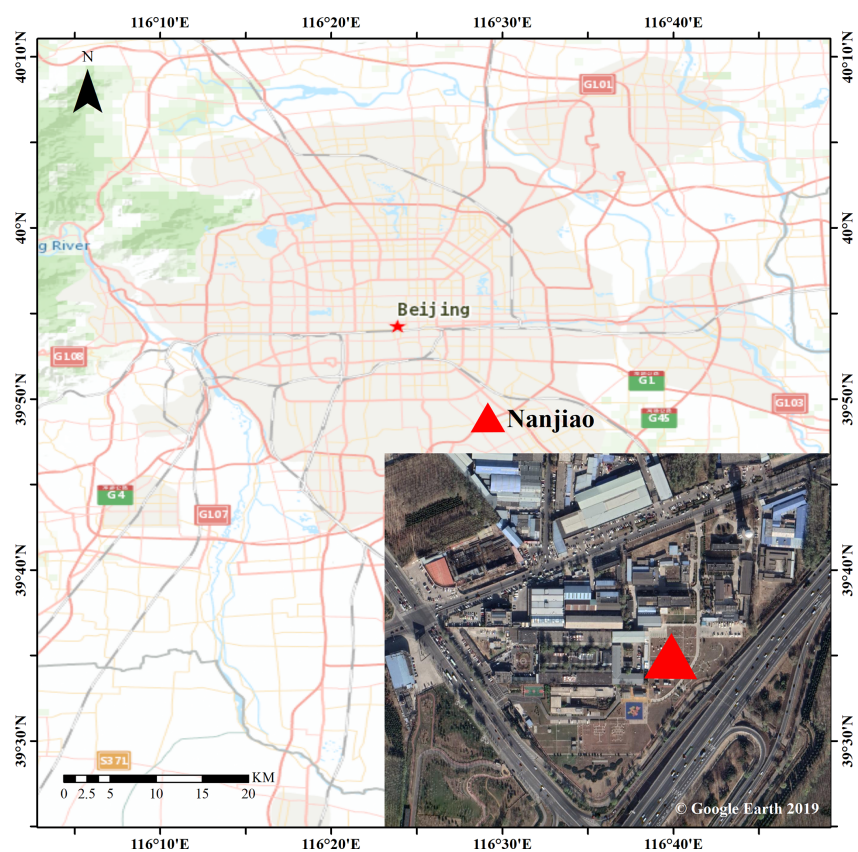

Figure 1. The map of the area surrounding the sampling site (Nanjiao) and true color image of the observation station. This map was made by ArcGIS (http://www.arcgis.com/index.html\#, last access: 17 February 2022). The true color image of the observation station is from (c) Google Earth 2019.

monodisperse aerosols by setting the voltage. The dry diameters $\left(D_{\mathrm{p}}\right)$ selected in this study were $40,80,110,150,200$, and $300 \mathrm{~nm}$ respectively. The selected quasi-monodisperse particles went either to the WCPC to obtain particle counts or through the heating tube for volatility measurements, sequentially at $80,150,200$, and $300^{\circ}$. Here, we focus on the data derived at $300^{\circ}$. After heating, the sample flow entered the $\mathrm{DMA}_{2}$ to scan the multi-dispersed particles and finally entered the WCPC to get the particle size distributions after heating, thereby obtaining the volatility shrink factor measured distribution function (VSF-MDF). Through inversion, the volatility shrink factor probability distribution function (VSF-PDF) was further obtained. The VSF-PDF was retrieved based on the TDMA $\mathrm{A}_{\text {inv }}$ algorithm developed by Gysel et al. (2009). The scans in which the temperature between the two DMAs was not increased were used to define the width of the transfer function. The residence time in the heated region was $2.4 \mathrm{~s}$ (Cheung et al., 2016). Compared with that of 0.3 to $1.5 \mathrm{~s}$ for other VTDMA systems (e.g., Brooks et al., 2002; Philippin et al., 2004; Villani et al., 2007; Jiang et al., 2018), the residence time in this VTDMA is sufficient for the volatile materials to be effectively vaporized. The relative humidity was verified periodically with ammonium sulfate during the measurement period. The result of the verification is shown in Fig. S2. It shows that the deliquescence RH of ammonium sulfate measured by H/V-TDMA is $\sim 78 \%$, which is consistent with the results reported by Badger et al. (2006) and Tan et al. (2013), indicating the RH measurement of this system is accurate. In addition to the volatility system, some other auxiliary instruments were used for simultaneous observation, including an aethalometer (AE33, Magee Scientific) for measuring the mass concentration of $\mathrm{BC}$, and a scanning mobility particle sizer (SMPS) for measuring the particle number size distribution (PNSD) of aerosols. Before the field measurement, all instruments used were calibrated to ensure the data obtained during the study period were accurate and reliable. The detailed calibration process of these auxiliary instruments can be found in Wu et al. (2020). The meteorological variables from the meteorological observation station were also used, including ambient temperature $(T), \mathrm{RH}$, wind direction (WD), and wind speed (WS).

\subsection{Method for retrieval of the mixing state of $\mathrm{BC}$}

In this study, we use the abbreviations Ex-BC, In-BC, and Non-BC to denote externally mixed, internally mixed, and non-BC-containing particles, respectively. The number fraction of the completely volatile particles $\left(\Phi_{\mathrm{CV}}\right)$ was calculated as

$\Phi_{\mathrm{CV}}=1-\frac{N_{\mathrm{r}}}{N_{D_{\mathrm{p}}} \cdot \eta_{D_{\mathrm{p}}, T}}$,

where $N_{\mathrm{r}}$ is number concentrations of the residual particles after heating, $N_{D_{\mathrm{p}}}$ is the number concentrations of $\mathrm{DMA}_{1}$ selected particles before heating, and $\eta_{D_{\mathrm{p}}, T}$ is the transportation efficiency of the sampled particles, which represents particle losses between $\mathrm{DMA}_{1}$ and $\mathrm{DMA}_{2}$ due to diffusion and thermophoretic forces (Philippin et al., 2004) and is always determined at each particle diameter and heating temperature with sodium chloride $(\mathrm{NaCl})$ particles in laboratory calibrations as they do not evaporate, even at high temperatures (Philippin et al., 2004; Cheung et al., 2016). In this study, $\eta_{D_{\mathrm{p}}, T}$ at each particle size is determined from the number concentration of $\mathrm{NaCl}$ particles before and after heating at $300^{\circ} \mathrm{C}$ (i.e. $\eta_{D_{\mathrm{p}}, T}=N_{\mathrm{r}}(\mathrm{NaCl}) / N_{D_{\mathrm{p}}}(\mathrm{NaCl})$ ). Due to the cubic shape of $\mathrm{NaCl}$ particles, a shape factor of 1.08 was used in the calibration process (Park et al., 2009; Hakala et al., 2017). The quantified number fraction of completely vaporized particles is shown in Figs. S3 and S4. We then classified the particles into three categories according to the measured VSF values (Wehner et al., 2009; Cheng et al., 2012):

- less-volatile (LV) - VSF $\geq 0.82$, considered to be Ex$\mathrm{BC}$;

- medium-volatility (MV) $-0.45 \leq \mathrm{VSF}<0.82$, considered to be In-BC;

- high-volatility (HV) - VSF $<0.45$, considered to be Non-BC.

The VSF-PDF $\left(c\left(\operatorname{VSFD}_{\mathrm{p}}\right)\right)$ was normalized as $\int c\left(\mathrm{VSF}, D_{\mathrm{p}}\right) \mathrm{dVSF}=1$. Then, the number fraction 
$\left(\Phi_{i}\right)$ for each volatile group with the boundary of $\left[\mathrm{VSF}_{\text {start }}\right.$, $\left.\mathrm{VSF}_{\text {end }}\right]$ is defined as

$\Phi_{i}=\left[\int_{\mathrm{VSF}_{\text {start }}}^{\mathrm{VSF}_{\mathrm{end}}} c\left(\mathrm{VSF}, D_{\mathrm{p}}\right) \mathrm{dVSF}\right] \cdot\left(1-\Phi_{\mathrm{CV}}\right)$,

where $i=\mathrm{Ex}-\mathrm{BC}$, In-BC or Non-BC. It is worth noting that when $i=$ Non-BC, those particles that completely evaporate were assumed to be included in the HV mode (considered as Non-BC), so $\Phi_{\text {Non-BC }}$ is calculated as

$\Phi_{\mathrm{Non}_{-B C}}=\left[\int_{\mathrm{VSF}_{\text {start }}}^{\mathrm{VSF}_{\text {end }}} c\left(\mathrm{VSF}, D_{p}\right) \mathrm{dVSF}\right] \cdot\left(1-\Phi_{\mathrm{CV}}\right)+\Phi_{\mathrm{CV}}$.

The number concentrations $\left(N_{i}\right)$ of In-BC, Ex-BC, and Non$\mathrm{BC}$ from the VSF distributions combined with the total PNSD simultaneously measured by the VTDMA are calculated as follows:

$N_{i}=\Phi_{i} \cdot N_{\text {total }}$.

Here, $N_{\text {total }}$ is the number concentration of ambient fine aerosol particles. Therefore, the actual number fractions of Ex-BC, In-BC and Non-BC particles before heating could be obtained.

The ratio of the $\mathrm{BC}$ diameter before and after heating at $300^{\circ} \mathrm{C}\left(D_{\mathrm{p}} / D_{\mathrm{c}}\right)$ was used as a quantitative index to characterize the coating thickness (degree of aging) of BC-containing particles. Here, particles with diameters of $150 \mathrm{~nm}$ are presented as examples (Fig. 2), $D_{\mathrm{p}}$ refers to the peak value of the $\mathrm{DMA}_{1}$ selected size distribution, and $D_{\mathrm{c}}$ refers to the peak diameter of residual particles after heating at $300^{\circ} \mathrm{C}$.

\subsection{Uncertainty analysis of the retrieval method}

Because this study investigates only the fine-mode particles below $300 \mathrm{~nm}$, refractory components that are present mostly in coarse-mode particles, e.g., dust and sea salt, are expected to be negligible. At around $300-350^{\circ} \mathrm{C}$, the refractory component in sub-micrometer aerosols in continental and urban areas has been considered to be mainly $\mathrm{BC}$ and a small contribution by charred organic material, which is often negligible (Rose et al., 2006; Frey et al., 2008; Wehner et al., 2009). Therefore, in this study, the retrieval of the mixing state of $\mathrm{BC}$ is based on the assumption that the refractory component in sub-micrometer aerosols consists mainly or solely of $\mathrm{BC}$. This assumption might not be true that there are some other important non-volatile aerosol compounds in submicron aerosols, for instance, some extremely low-volatility organic material that does not evaporate even at $300^{\circ} \mathrm{C}$ (Cappa and Jimenez, 2010; Häkkinen et al., 2012; Poulain et al., 2014; S. L. Zhang et al., 2016; Z. Wang et al., 2017).

To investigate the composition of the refractory component and verify whether they consist mainly of BC, we first

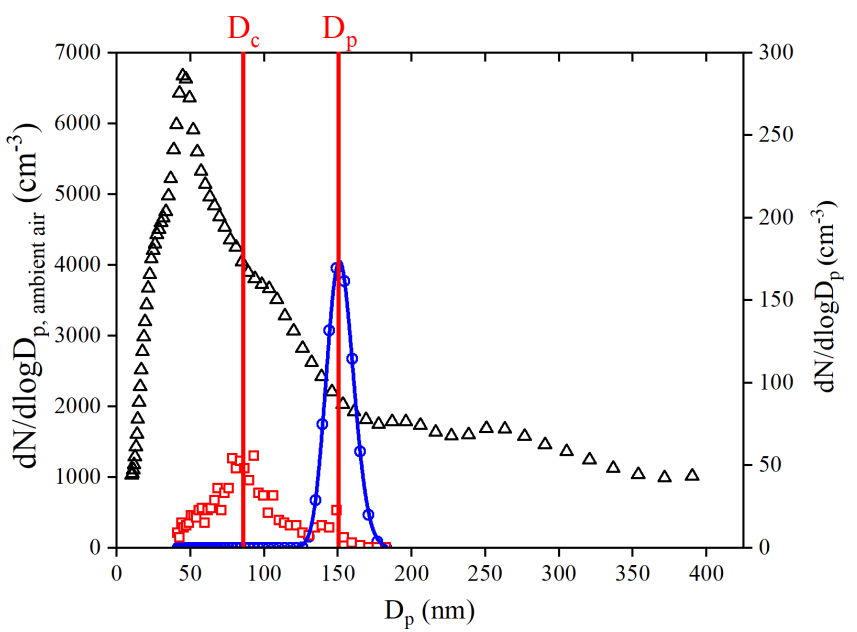

Figure 2. Particle number size distribution (PNSD) of ambient aerosols (in black), $\mathrm{DMA}_{1}$-selected particles with $D_{\mathrm{p}}$ equal to $150 \mathrm{~nm}$ (in blue), residual particles after heating at $300^{\circ}$ (in red), and the fitting curves.

quantify the bulk mass concentration of these non-volatile material. For the calculation, the number concentration of the residual non-volatile particles at each size $(40,80,110$, 150,200 , and $300 \mathrm{~nm}$ ) is calculated by integrating the residual PNSD of each selected particle size that was directly measured by VTDMA at the temperature of $300^{\circ}$. Then, the size-resolved mass concentration of the residual non-volatile particles was calculated by assuming the particles are spherical and with a density of $1.6 \mathrm{~g} \mathrm{~cm}^{-3}$ (Häkkinen et al., 2012; Poulain et al., 2014). Finally, by fitting the size-resolved mass concentration and integrating the fitted curves, the bulk mass concentration of non-volatile particles was retrieved. The retrieved bulk mass concentration of non-volatile particles was correlated with the $\mathrm{BC}$ mass concentrations measured by AE33, which are shown in Fig. 3. The calculated non-volatile particle mass concentration and the measured BC concentration correlated well, with a slope of 1.02. The mass fraction of non-volatile compounds except $\mathrm{BC}$ was further evaluated, which accounted for $\sim 1.8 \%$. Consequently, at $300^{\circ} \mathrm{C}$, the contribution of non-volatile organic aerosol (OA) factors is expected to be quite negligible $(<5 \%)$. This result suggests that $\mathrm{BC}$ can explain almost all of the mass fraction of the nonvolatile material in this study. In addition, we also compared the mean VSF measured at 200 and $300^{\circ} \mathrm{C}$. Results show that the VSF values varied greatly under different heating temperatures, especially for large particles (Fig. S5); hence some studies (Xu et al., 2016; Cappa and Jimenez, 2010) that obtained considerable non-volatile $\mathrm{OA}$ at $250^{\circ} \mathrm{C}$ may differ from the fractions at $300^{\circ} \mathrm{C}$.

To further verify the reliability of the retrieved results, the number fraction of Ex-BC and In-BC for $200 \mathrm{~nm}$ particles calculated from the VTDMA is compared with the measurements by a single-particle aerosol mass spectrometer 


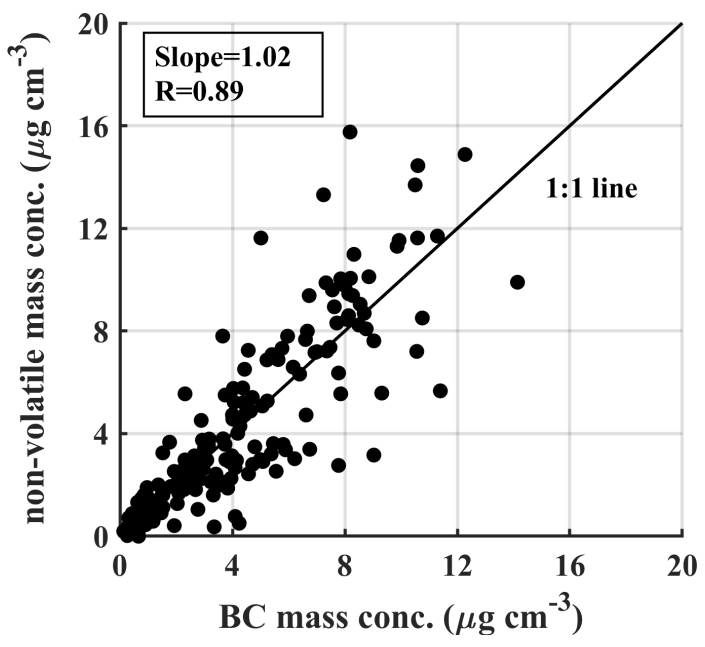

Figure 3. Black carbon (BC) mass concentration measured by AE33 vs. the non-volatile mass concentration estimated from the VTDMA for the winter 2019 period. Estimation of the non-volatile mass concentration was made assuming a density of $1.6 \mathrm{~g} \mathrm{~cm}^{-3}$.

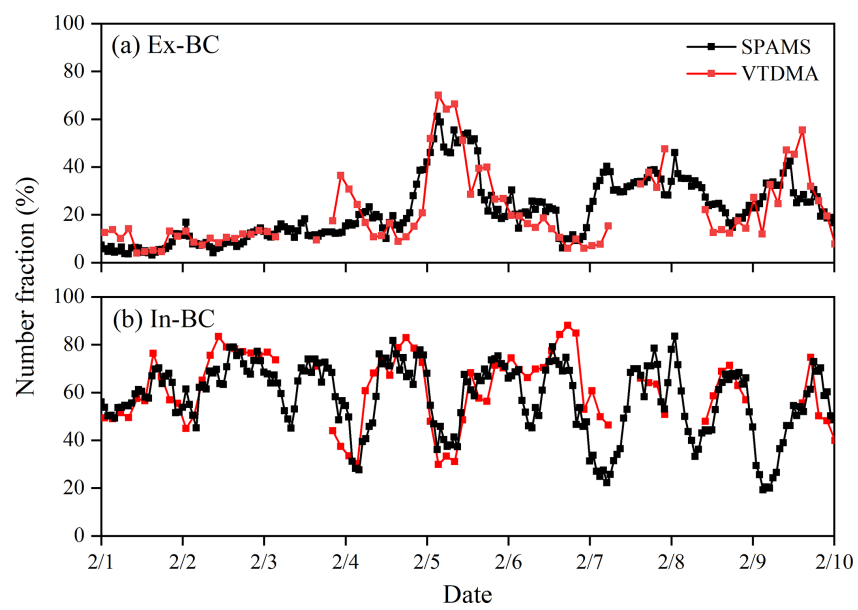

Figure 4. Time series of number fraction of (a) Ex-BC particles and (b) In-BC particles measured by SPAMS (in black) and calculated from VTDMA (in red); the $200 \mathrm{~nm}$ particles from VTDMA and SPAMS are chosen for comparison (1-10 February 2019).

(SPAMS), as shown in the Fig. 4. The comparison can only be confined to the size of $200 \mathrm{~nm}$ because it is the lower limit of the measured size for SPAMS (Bi et al., 2015). This shows that the variations of number fractions of both the Ex-BC and In-BC particles retrieved from VTDMA are very consistent with those measured by SPAMS, confirming that the method is reliable for deriving the mixing state of $\mathrm{BC}$ during the campaign in urban Beijing.

\section{Results and discussion}

\subsection{Time series of the VSF-PDF}

Figure 5 shows the time series of the meteorological parameters, $\mathrm{PM}_{2.5}$ concentration, and the VSF-PDF during the winter and summer campaign periods. The $T$ and $\mathrm{RH}$ display diurnal cycles. The average $T$ and $\mathrm{RH}$ are $0.3{ }^{\circ} \mathrm{C}$ and $35 \%$ during the winter and $28.3^{\circ} \mathrm{C}$ and $69 \%$ during the summer. The dominant winds at the site are from the north in the winter and from the south in the summer. The wind speed during the two field campaigns ranged from 2 to about $6 \mathrm{~m} \mathrm{~s}^{-1}$. More polluted episodes with $\mathrm{PM}_{2.5}$ concentration of $>200 \mu \mathrm{g} \mathrm{m}^{-3}$ were more frequent in the winter than in the summer, when the $\mathrm{PM}_{2.5}$ concentration was $<100 \mu \mathrm{g} \mathrm{m}^{-3}$ on most of the observed days. Figure $5 \mathrm{~d}$ and e display time series of measured VSF-PDF for $\mathrm{DMA}_{1}$-selected particle sizes of 40 and $150 \mathrm{~nm}$ during the two periods. In the summer, the VSF distributions of $40 \mathrm{~nm}$ particles were almost always bimodal, with a non-volatile mode (the VSF was approximately equal to 1) and a high volatile mode (with VSF of about $0.2-0.5$ ). As stated above, we attribute the non-volatile group to refractory BC particles. In the winter, the VSF-PDF was bimodal only occasionally and mostly on polluted days, which could be caused by changes in meteorology and enhanced primary $\mathrm{BC}$ emissions during polluted days in the winter. For the $150 \mathrm{~nm}$ particles, the distributions were generally unimodal, with VSF of about $0.3-0.6$ in the winter, but were almost bimodal with a non-volatile mode and a high-volatility mode in the summer, indicating the mixing and aging of the primary particles during growth to larger sizes during the winter sampling periods. The VSF in the summer fluctuated a bit less than that observed in the winter, which will be further discussed in the following section.

\subsection{Comparison of the VSF-PDF between summer and winter and trajectory analysis}

Comparison of the average VSF-PDF distribution for all measured dry particle sizes during the winter and summer period is illustrated in Fig. 6. The mean VSF-PDFs are bimodal, with one high-volatility and one less- or non-volatile mode both in the summer and winter. But the mean VSFPDFs possess an HV mode in the summer, generally with peak values of $\sim 0.2$, while an MV mode is present across the size range in the winter (with peak values of 0.45-0.65), indicating higher volatility of the aerosol particles in the summer. In addition, the modes in the VSF-PDFs for the different dry sizes are much broader in the winter than in the summer, reflecting greater heterogeneity in chemical composition.

Our results from Beijing are consistent with those reported previously for other urban environments, with Kuhn et al. (2005), Cheung et al. (2016), Cai et al. (2017), and Jiang et al. (2018) reporting that the VSF-PDFs of fine particles normally have both LV and HV/MV modes. The LV 

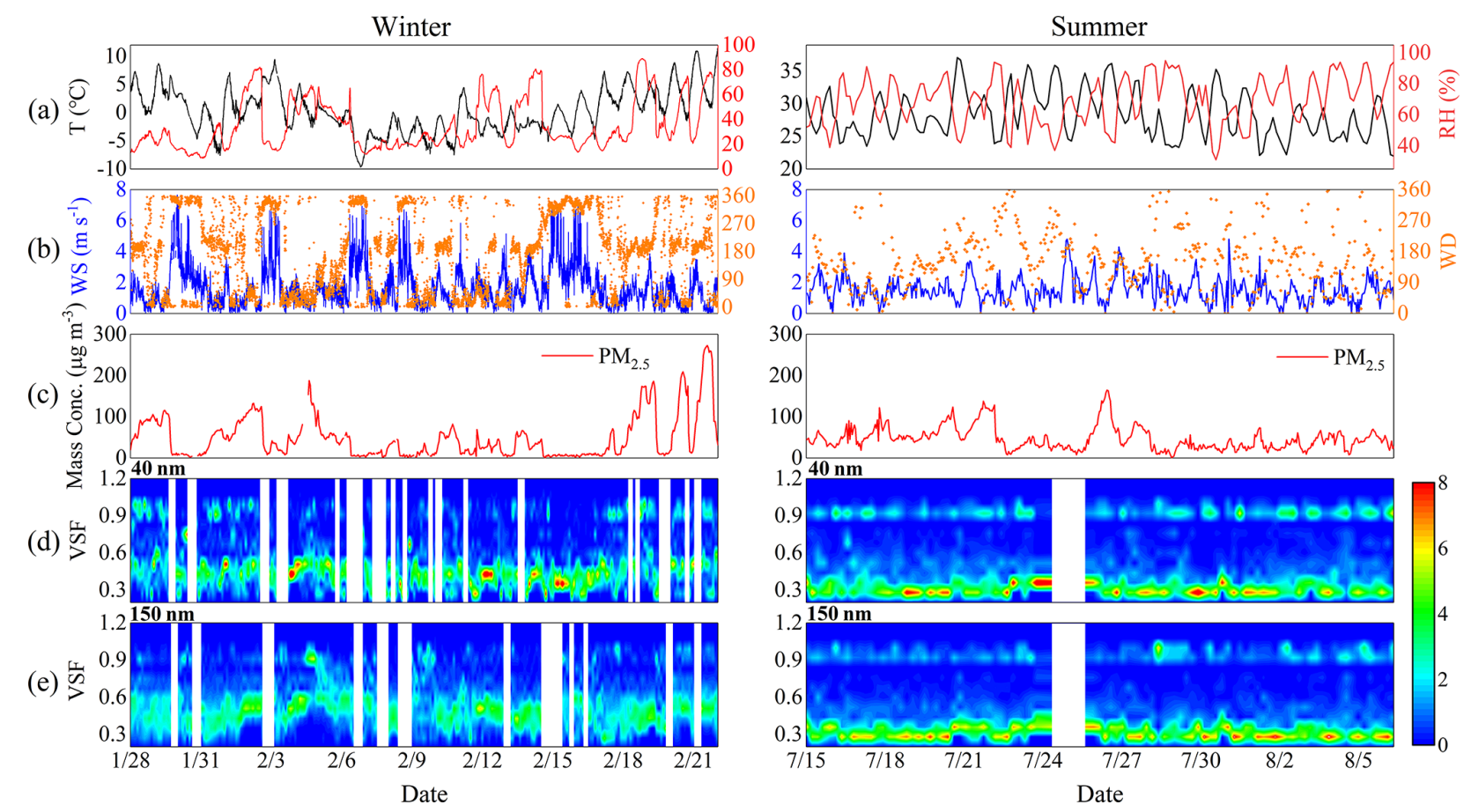

Figure 5. Time series of (a) ambient temperature $(T)$ and relative humidity $(\mathrm{RH})$, (b) wind direction and wind speed, (c) mass concentration of $\mathrm{PM}_{2.5}$, and (d-e) volatility shrink factor distributions (VSF-PDF) for 40 and $150 \mathrm{~nm}$ particles at $T=300^{\circ}$ during the winter (left) and summer (right) periods.

mode consists of non-volatile particles, like BC, the MV mode is comprised of a mixture of volatile (e.g., organics) and non-volatile matter, and the HV mode generally consists of volatile materials that tend to evaporate when heated. In this study, the prominent MV mode in the winter suggests the dominant pathway for fine particle growth is coagulation and condensation of more volatile species (organics or inorganic salts) on non-volatile primary particles (e.g., BC), while the prominent $\mathrm{HV}$ mode in the summer especially for large particle size could be due to condensation of semi-volatile materials on nucleated particles (Riipinen et al., 2012).

Figure 7 presents the $72 \mathrm{~h}$ back trajectories arriving at the sampling site during the two periods from 00:00 to 23:00 LT calculated applying TrajStat software (Wang et al., 2009) (Fig. 7a) and the size-resolved mean VSF $\left(\mathrm{VSF}_{\text {mean }}\right)$ of the corresponding cluster during the winter and summer periods (Fig. 7b). In the winter, the air masses were categorized into five clusters and with prevailing northerly wind. The northwest clusters (C2 and $\mathrm{C} 3$ ) were predominant, which were associated with the high $\mathrm{PM}_{2.5}$ concentrations (Wang et al., 2015). The $\mathrm{VSF}_{\text {mean }}$ of small particle size among different clusters shows greater variability than that of large size, implying more diverse sources of small particles. In the summer, the air masses were classified into six clusters, with prevailing southerly wind ( $\mathrm{C} 1$ and $\mathrm{C} 3)$. It shows that the $\mathrm{VSF}_{\text {mean }}$ values in both the winter and summer were independent of the variations of trajectories, or the impacts of re- gional transportation on volatility of the fine aerosol particles are complex. Obviously, the seasonal differences in $\mathrm{VSF}_{\text {mean }}$ are more significant than those among different clusters, especially for larger size particles.

\subsection{Comparison of diurnal variation of particles' volatility between summer and winter}

To obtain further insights into the effect of the formation and growth of particles on their volatility, we compare the diurnal variations of the observed mean VSF and VSF-PDF between the summer and winter (Fig. 8). Here, the VSFPDFs of 40 and $150 \mathrm{~nm}$ particles are shown. Although the local primary emission sources (e.g., vehicles and cooking) can contribute to the preexisting background small particles in urban environments, the fraction was probably lower during the new particle formation (NPF) events. It was reported that the ultrafine particles during clear days (e.g., NPF days) in urban Beijing were primarily from secondary formation (Wang et al., 2018), and the preexisting particles are predominant in accumulated mode. During the summer, low VSF during the daytime (08:00-18:00 LT) and high VSF during the nighttime were observed for 40 and $150 \mathrm{~nm}$ particles (Fig. 8a). Accordingly, the VSF-PDF shows the HV mode dominated around noon and early afternoon, and the LV mode dominated during nighttime (Fig. 8c and e). The diurnal variation is more evident for small particles (e.g., $40 \mathrm{~nm}$ ) than for larger particles (e.g., $150 \mathrm{~nm}$ ). The diurnal 


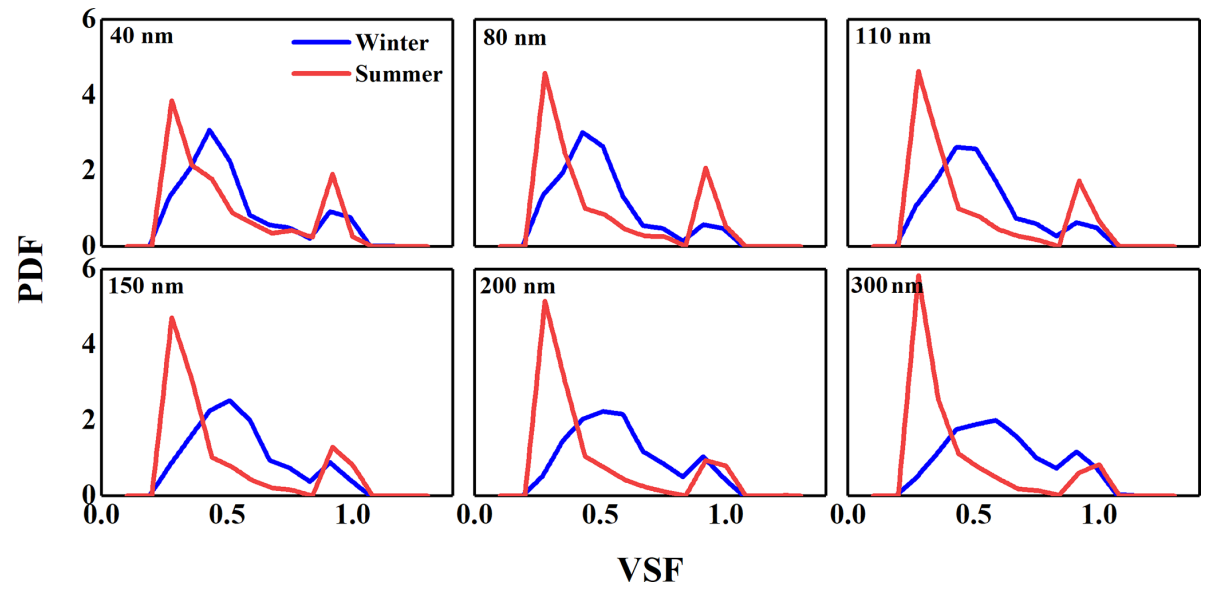

Figure 6. Average volatility shrink factor (VSF) distributions for different sizes (40-300 nm) during the winter (in blue) and summer (in red) observations.

variations illustrate that particles are more volatile during the daytime than at night, with VSF decreasing dramatically after $\sim 10: 00$ LT. Figure $8 \mathrm{~g}$ displays the mean diurnal variations of PNSDs in the summer. During the summer sampling periods, NPF events took place frequently, with 10 NPF events occurring (Fig. S6). The NPF events almost all started at around 10:00 LT. After the starting of NPF, the volatile mode in VSF-PDF was obviously enhanced, corresponding to significant decreases of the mean VSF values. Although the NPF process requires low-volatility vapors to form molecular clusters and nuclei (Ehn et al., 2007), the significant high-volatility mode around noon on NPF days indicates partitioning of volatile substances into the growing particles in the summer. A previous study also showed that the growth process of the nucleated particles primarily formed non-refractory sulfate and organics in Beijing (Wehner et al., 2009). Wu et al. (2017) also observed a clear decrease in VSFs for 30 and $50 \mathrm{~nm}$ particles in a rural area of north China during the NPF events, indicating that volatile compounds could be produced during the growth process of newly formed particles. However, some earlier campaign measurements that were conducted in various atmospheric environments, such as urban (Sakurai et al., 2005) and forest (Ehn et al., 2007), showed that the volatility of newly formed particles varied with the atmospheric environment, indicating distinct particle growth mechanisms. In addition, during the daytime, atmospheric aging processes facilitated the mixing of primary particles (e.g., BC) with secondary species, leading to the transformation of externally mixed particles to internally mixed particles. In the evening and the early morning, the number fraction of LV-mode particles increased because of increased emissions of refractory particles (like BC) from traffic and other primary sources, coupled with slower particle aging and weaker vertical mixing that concentrates the externally mixed BC close to the surface (S. L. Zhang et al., 2016).
Compared with that in the summer, there was little diurnal variation in VSF during the winter period (Fig. 7b), and an MV mode was present in the VSF-PDFs for both 40 and $150 \mathrm{~nm}$ particles during the daytime (Fig. 8d and f). This is likely because of weakened photochemistry during the daytime in the cold season, when fewer NPF events were observed (Fig. 8h). In addition, the number fraction of the LV mode for both 40 and $150 \mathrm{~nm}$ particles is much lower during the winter (Fig. 8c-f). This may reflect the fact that $\mathrm{BC}$ particles can be coated and aged quickly through heterogeneous reactions of volatile organic compounds (VOCs) and other precursor gases (like $\mathrm{SO}_{2}$ and $\mathrm{NO}_{x}$ ) (Zhang et al., 2020), which are usually more concentrated during polluted days in the winter (Sun et al., 2016a). However, the aging process is expected to be slowed in the summer when anthropogenic precursor concentrations are lower. Such an explanation is reasonable and can be supported by the observed thicker coating layer in the winter, as characterized by $D_{\mathrm{p}} / D_{\mathrm{c}}$ (shown in Fig. 12; see Sect. 3.6).

\subsection{Number concentrations and fractions of Non-BC, In-BC, and Ex-BC}

To study the aerosol mixing state, we retrieved the number concentrations of Non-BC, In-BC, and Ex-BC from the VSF data (Fig. 9). The time series of number concentrations and fractions of $150 \mathrm{~nm}$ particles are presented in Fig. 9a and b (see Figs. S7 and S8 for the time series of other sizes). Both in the summer and winter cases, large temporal variations in the number concentrations and fractions of Non-BC, In-BC, and Ex-BC were observed, which reflects influences from both local primary urban emissions and addition of secondary species. In the summer, most particles were Non$\mathrm{BC}$ (with a mean number fraction of $\sim 67 \pm 9 \%$ ) because of large contributions from particles formed through condensation of semi-volatile materials, while In-BC accounted 
(a)
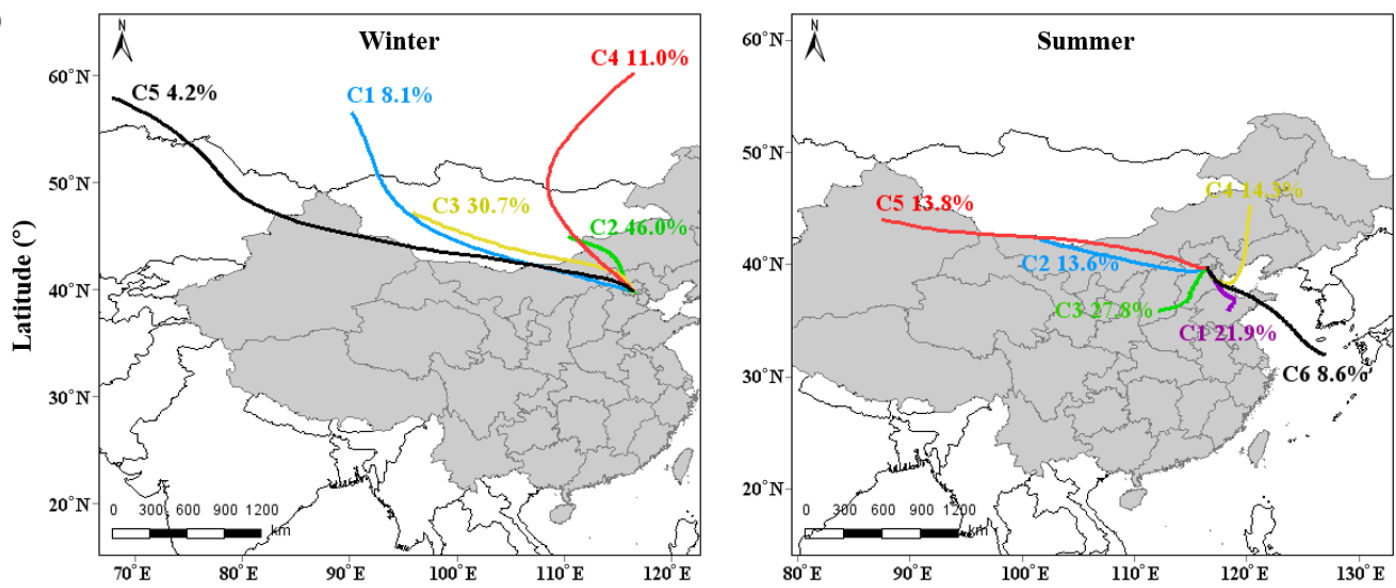

(b)

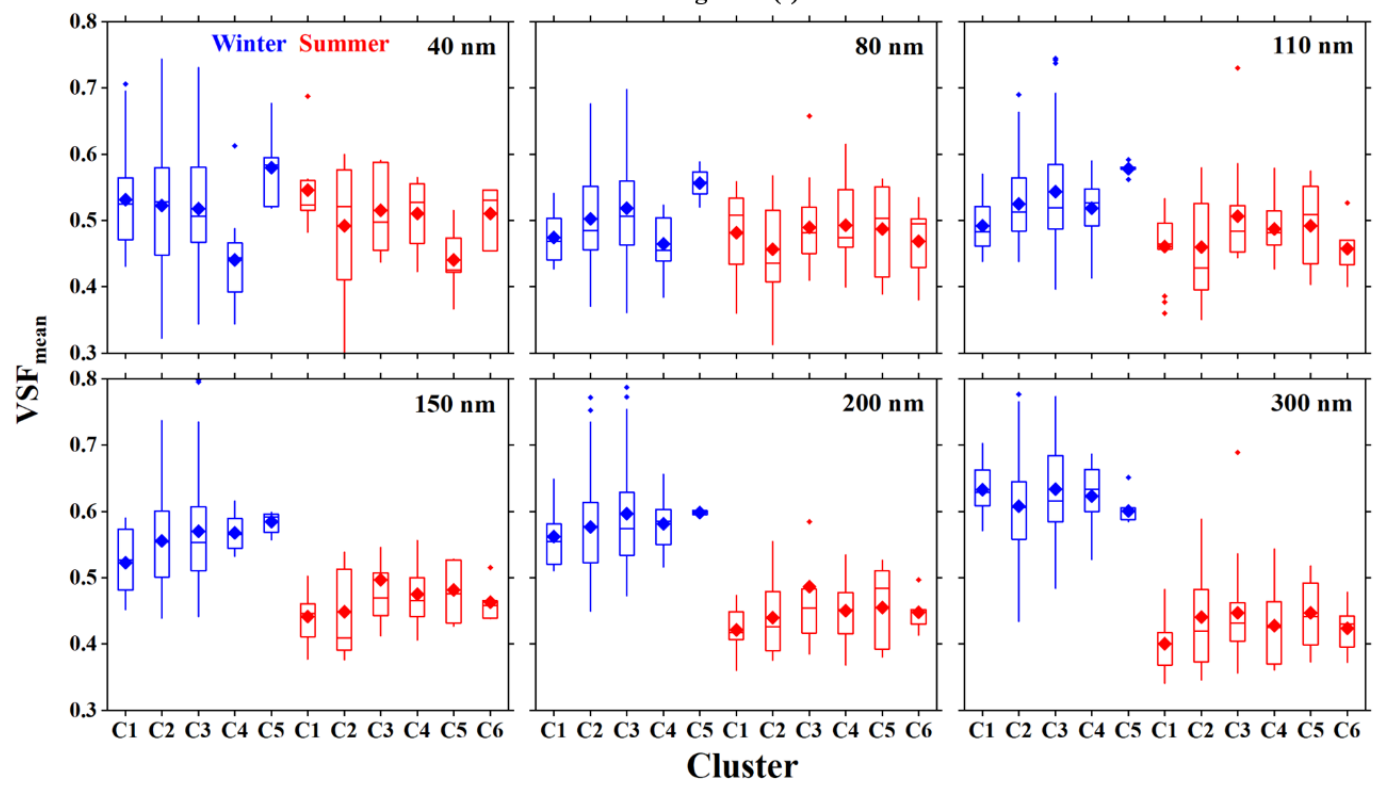

Figure 7. (a) The $72 \mathrm{~h}$ back trajectories arriving at the Nanjiao site during the winter (left) and summer (right) periods. C1-C6 represent Cluster 1-Cluster 6 respectively. The percentages present the relative occurrences. (b) Box diagram for the mean volatility shrink factor $\left(V_{\text {SF }}\right.$ mean $)$ of all selected diameter particles $(40-300 \mathrm{~nm}$ ) from different clusters during the winter (blue) and summer (red) periods. The horizontal line in the block diagram represents the median, the diamond represents the mean, the upper and lower borders represent the 25 th and 75th percentiles, and the upper and lower borders of the dotted vertical line represent the 10th and 90th percentiles.

for a small proportion $(\sim 23 \%)$. In contrast to the summer case, the majority of particles were In-BC in the winter, with a number fraction of $\sim 55 \pm 11 \%$, reflecting efficient aging and coating of BC particles. Large Non-BC number concentrations and fractions were also observed by Zhang et al. (2017) in the summer at a site in Xianghe (a suburb site close to urban Beijing), where most ambient aerosol particles are Non-BC, with only $7 \%-10 \%$ of particles containing $\mathrm{BC}$. The Ex-BC represents the smallest proportion both in the winter and summer, with number fractions of $\sim 13 \pm 10 \%$ and $\sim 10 \pm 7 \%$ respectively, suggesting rapid aging and mixing of freshly emitted $\mathrm{BC}$ with other species.
Figure 10 illustrates the size dependence of the total number fractions of the Non-BC, In-BC, and Ex-BC particles during the summer and winter periods. The number fractions of Non-BC and In-BC are highly size-dependent. In the summer, the number fraction of Non-BC increased with increasing particle size, accounted for $52 \%-69 \%$ of the total number concentration, further demonstrating the large contribution of condensation of semi-volatile materials to the total concentration of particles and the absence of refractory materials (like BC) participating in their growth. In the winter, the number fraction of In-BC increased, and the number fraction of Non-BC decreased with increasing particle size, and $\mathrm{BC}$-containing particles (including Ex-BC and In-BC) 
(a)

(c)

(e)

(g)

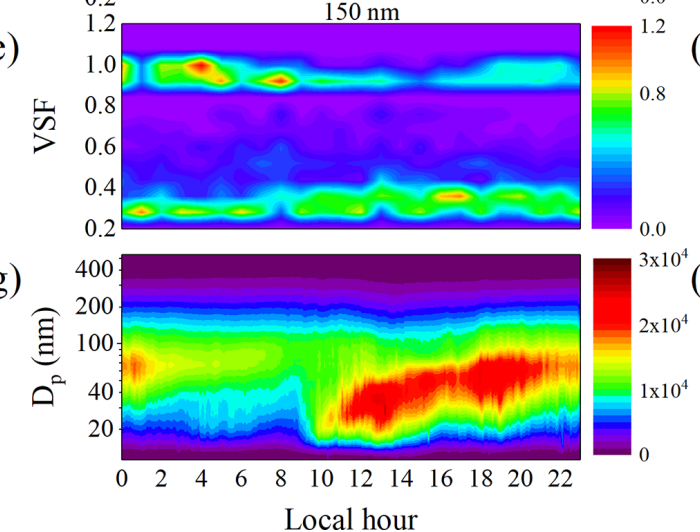

Summer

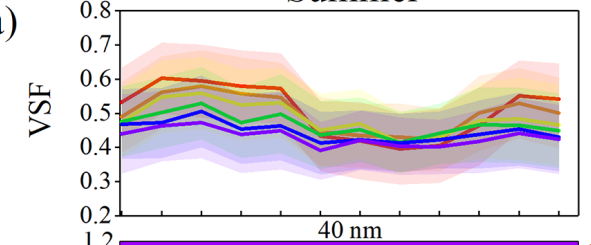

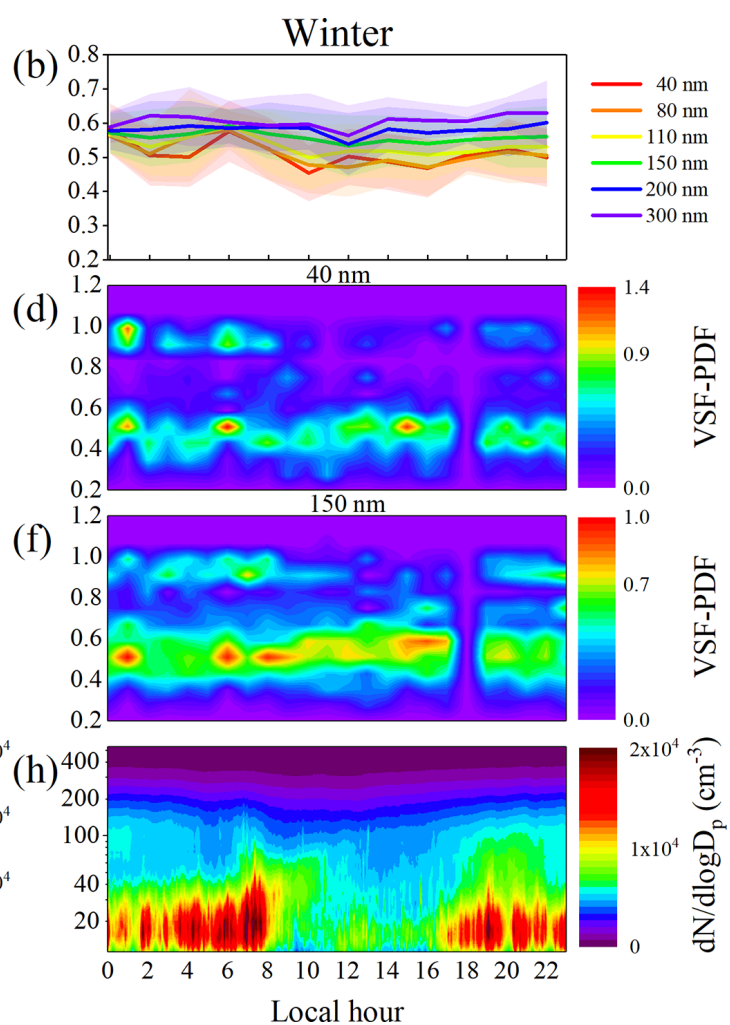

Figure 8. Diurnal variation of (a-b) mean VSF for all measured dry particle sizes, (c-f) mean VSF-PDF for 40 and $150 \mathrm{~nm}$ particles, and (g-h) mean particle number size distribution during the summer (left) and winter (right) periods. The shaded regions in (a)-(b) denote the standard deviations.

dominate and contribute $67 \%-77 \%$ toward the total number concentration, which again suggests that the particles in this size range result from the growth of non-volatile primary aerosols (e.g., BC) through addition of more volatile components from coagulation and condensation.

In summary, during the winter most ambient aerosol particles were $\mathrm{BC}$-containing, suggesting that $\mathrm{BC}$ particles are a dominant component in urban Beijing. In the summer, however, BC-containing particles contributed much less (only $31 \%-48 \%$ ) toward the total number concentration in the measured size range, while Non-BC particles originating from condensation of semi-volatile materials are the dominant particle type.

\subsection{Diurnal variations of retrieved number concentrations and fractions of Non-BC, In-BC, and Ex-BC}

Figure 11 shows the diurnal variations of number concentrations and fractions of Non-BC, In-BC, and Ex-BC of 40 and $150 \mathrm{~nm}$ particles for the summer and winter cases. Diurnal variations are evident for 40 and $150 \mathrm{~nm}$ Non-BC particles. In the summer, there is a continuous increase in the number concentration and fraction of Non-BC from 10:00 to 14:00 LT, reflecting the impact of new particle forma- tion and growth. The increase in concentration/fraction for $150 \mathrm{~nm}$ Non-BC particles extended into the late evening (23:00 LT) as particles that nucleated earlier in the day continued to grow into that size range. Compared to the summer, the Non-BC concentration/fraction in the winter was lower during daytime and higher during nighttime, with the average number concentration of $\sim 1470 \mathrm{~cm}^{-3}$ during nighttime (21:00-05:00 LT), corresponding to a number fraction of $\sim 40 \%$, but only $\sim 942 \mathrm{~cm}^{-3}(\sim 30 \%)$ during daytime (06:00-20:00 LT). This illustrates that the diurnal changes in the planetary boundary layer (PBL) dominate the diurnal patterns of Non-BC in the cold season when the sources (e.g., nucleation) of Non-BC are insignificant.

The diurnal cycles for In-BC are insignificant both in the summer and winter. A slight increase in the number concentration of In-BC is observed during the daytime in the summer for $150 \mathrm{~nm}$ particles, likely resulting from rapid photochemical aging that converts the Ex-BC into In-BC particles. However, in the winter, photochemistry and the rate of aging of Ex-BC are reduced, and therefore little or no increase of In-BC around noon is observed. Instead, its number concentration decreases slightly in the early afternoon (around 14:00 LT) because of the increase in PBL height, resulting in dilution of aged particles with the less polluted air from higher up (Rose et al., 2006). The diurnal variations of num- 
(a)

(b)
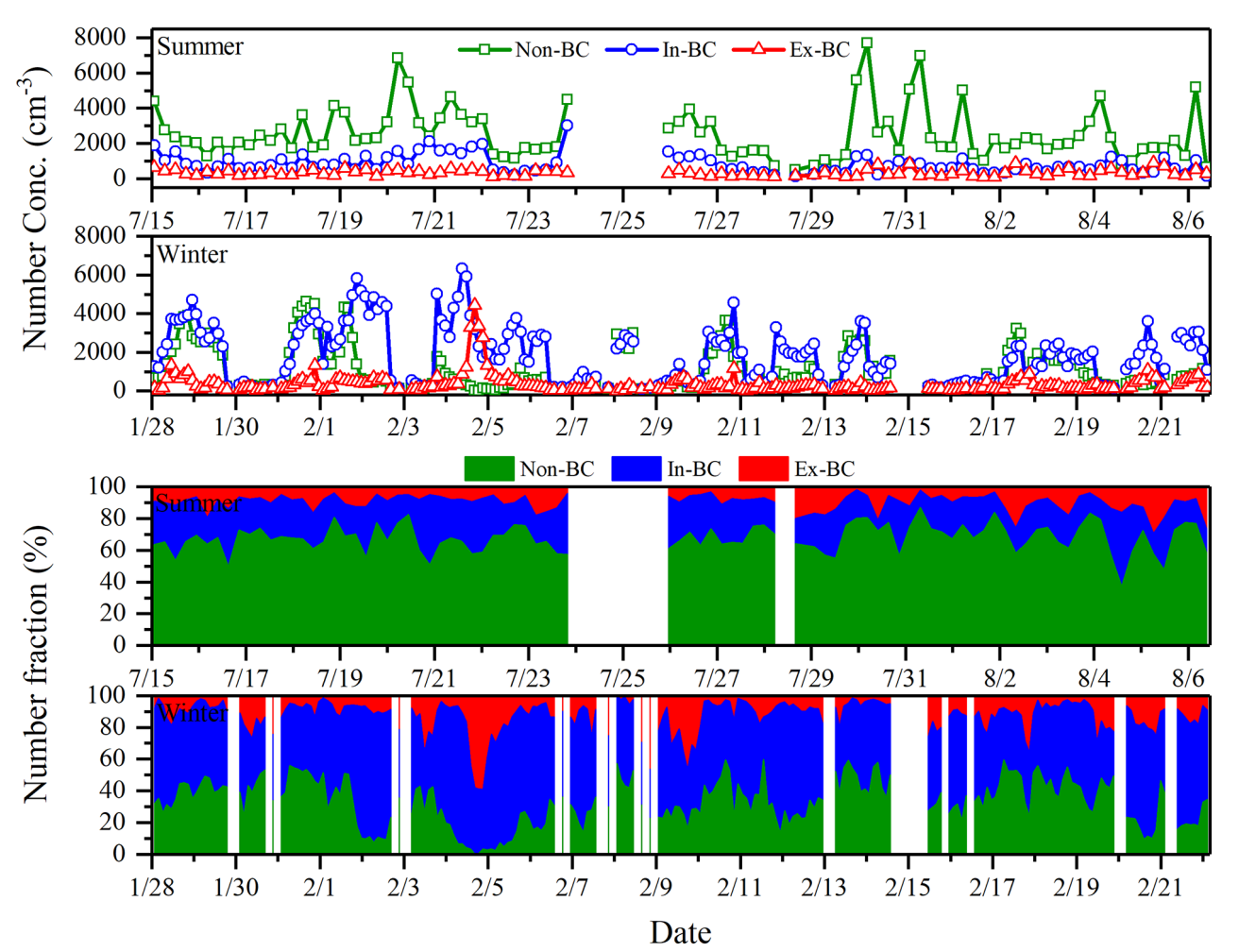

Figure 9. Summer (top) and winter (bottom) time series of (a) number concentrations and (b) number fractions of Non-BC (in green), In-BC (in blue), and Ex-BC (in red) of $150 \mathrm{~nm}$ particles.
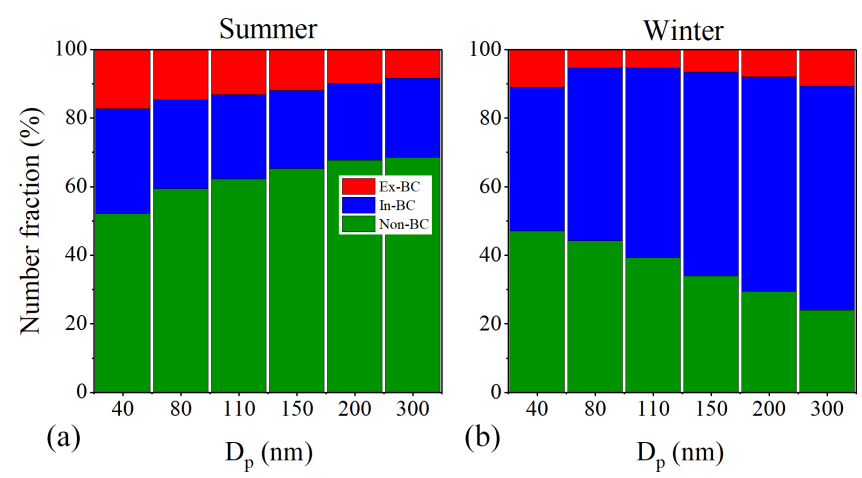

Figure 10. Size-resolved, campaign-averaged number fractions of Non-BC, In-BC, and Ex-BC during the winter (a) and summer (b) periods.

ber concentrations and fractions of Ex-BC have minima during the daytime and maxima at night for both the summer and winter, consistent with diurnal variations of the PBL height and patterns in urban traffic, which emits fresh Ex-BC particles. These results are in general agreement with previous observations in similar urban environments such as those described by Cheung et al. (2016) and Cheng et al. (2012).

In summary, the diurnal variation of aerosol mixing state reflected competition among the processes of photochemical aging, nucleation, local primary emissions, and changes of PBL height. In the summer, photochemical production and growth of particles are the main contributors to Non-BC particles. The rates of aging of $\mathrm{BC}$ particles in the urban atmosphere may be similar throughout the day, as suggested by the insignificant diurnal variations of In-BC concentration and fraction. In addition to local vehicle emissions and incomplete combustion of fossil fuel, the diurnal variations of Ex-BC concentration are largely impacted by variations of the PBL.

\subsection{Coating thickness characterized by $D_{\mathrm{p}} / D_{\mathrm{C}}$ ratio}

In the winter, most $\mathrm{BC}$ particles have $D_{\mathrm{p}} / D_{\mathrm{c}}$ ratios of 1.6-2.6 (Fig. S9). The large $D_{\mathrm{p}} / D_{\mathrm{c}}$ ratios suggest that the $\mathrm{BC}$ particles are thickly coated and likely have a compacted structure following atmospheric aging that results from additional emissions from the residential heating sector and favorable condensation because of the low temperature. During the summer, the coatings on BC were thinner, with an average $D_{\mathrm{p}} / D_{\mathrm{c}}$ of 1.5 (Fig. 12). In addition, in the winter the $D_{\mathrm{p}} / D_{\mathrm{c}}$ ratio was highly dependent on particle size, with decreasing coating layer thickness with increasing particle size. In the summer, it was independent of particle size.

Our results are similar to those reported previously in similar urban environments (Wehner et al., 2004; Zhang et al., 

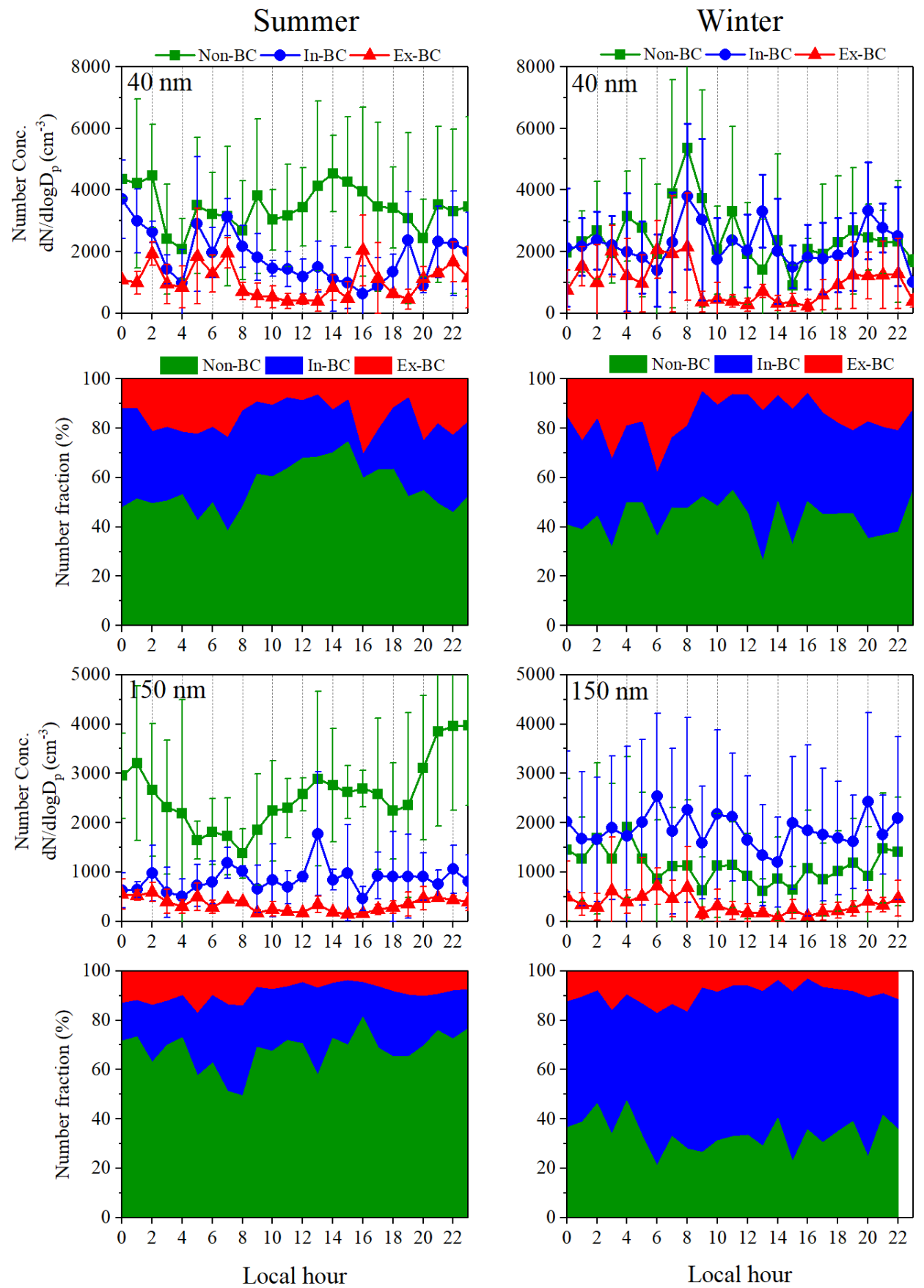

Figure 11. Average diurnal variations of retrieved number concentrations and fractions of Non-BC, In-BC, and Ex-BC of 40 and $150 \mathrm{~nm}$ particles in the summer (left) and winter (right) periods.

2018; Liu et al., 2019). For example, Liu et al. (2019) found $\mathrm{BC}$ coating thickness was more variable in the winter than in the summer and that the average coating thickness on $\mathrm{BC}$ particles was higher in the winter. Zhang et al. (2018) showed that the size dependence of the $D_{\mathrm{p}} / D_{\mathrm{c}}$ ratio was associated with air pollution and indicated that the aging of smaller BC cores was more sensitive to air pollution levels.
Previous modeling studies have reported that coating materials on $\mathrm{BC}$ particles can significantly enhance the light absorption of BC via the lensing effect (Jacobson, 2001; Moffet and Prather, 2009; Lack and Cappa, 2010; Zhang et al., 2020). Thus, aging of BC-containing particles enhances their light absorption efficiency. However, how the aging and light absorption capability of $\mathrm{BC}$ particles will change under different ambient conditions remains unclear. The differences 


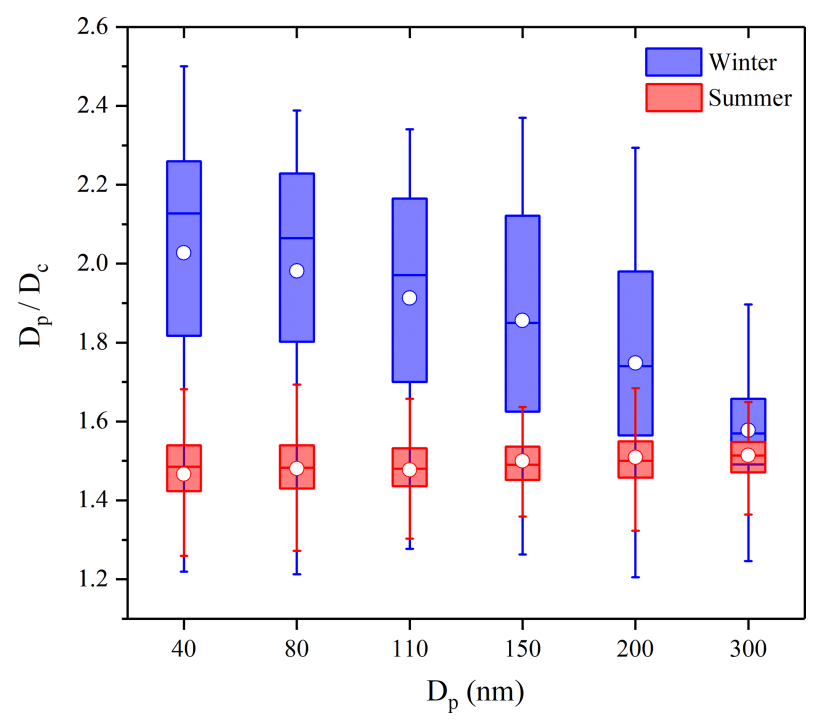

Figure 12. Size-dependent mean $D_{\mathrm{p}} / D_{\mathrm{c}}$ ratio (circular markers) of fine aerosol particles during the winter (in blue) and summer (in red) periods. The boxes show the 25 th, 50 th, and 75 th percentiles. The extremities show the 5 th and 95 th percentiles.

in coating thickness on BC particles we observed between summer and winter can help to parametrize the BC absorption enhancement in models.

\section{Conclusions}

In this study, the volatility of the fine particles is characterized as VSF, and the results from wintertime and summertime are shown and compared. Results show that the measured VSF-PDF is almost always bimodal, with one highvolatility and one less- or non-volatile mode, both in the summer and winter. The mean VSF-PDF has a pronounced $\mathrm{HV}$ mode in the summer, generally with a VSF minimum at $\sim 0.2$, while in the winter a broad MV mode spans much of the measured VSF range (with VSF minimum at 0.450.65 ), reflecting lower average volatility in the winter. Diurnal variations in VSF of $40 \mathrm{~nm}$ particles are evident only in the summer, with a prominent HV mode present around noon and early afternoon and a dominant LV mode during nighttime. No such feature is evident in the winter measurements. The mixing state of ambient fine particles was calculated from the size-resolved VSF and the results for summer and winter compared and contrasted. On average, nucleation and particle growth result in a dominant population of volatile, Non-BC particles, which account for 52\%-69\% of the total concentration in the measured size range in the summer. However, black carbon (BC)-containing particles contributed $67 \%-77 \%$ toward the total number concentration in the winter, indicating that $\mathrm{BC}$ particles are a dominant component of the wintertime Beijing. The diurnal cycles of the retrieved particle mixing state in the summer further show that rapid photochemical processing and nucleation are the main contributors to Non-BC particles. By analyzing the ratio of the $\mathrm{BC}$ particle diameter before and after heating at $300^{\circ} \mathrm{C}$, we show that the $\mathrm{BC}$ particles are more thickly coated in wintertime than in summertime. The observed results on aerosols volatility and mixing state in this study can help understand the formation and growth of fine particles and determine their effect on the environment and climate.

Data availability. All data needed to evaluate the conclusions in the paper are present in the paper and/or the Supplement. All data used in the study are also available from the corresponding author upon request (zhangfang2021@ hit.edu.cn).

Supplement. The supplement related to this article is available online at: https://doi.org/10.5194/acp-22-2293-2022-supplement.

Author contributions. FZ and LC conceived the conceptual development of the manuscript. LC directed and performed of the experiments with JL, SJ, JR, and FZ, and LC conducted the data analysis and wrote the draft of the manuscript. All authors edited and commented on the various sections of the manuscript.

Competing interests. The contact author has declared that neither they nor their co-authors have any competing interests.

Disclaimer. Publisher's note: Copernicus Publications remains neutral with regard to jurisdictional claims in published maps and institutional affiliations.

Acknowledgements. This work was funded by NSFC research projects $(41975174,41675141)$, the National Basic Research Program of China (2017YFC1501702), and the BNU Interdisciplinary Research Foundation for the First-Year Doctoral Candidates (grant BNUXKJC2126). We thank all participants in the field campaigns for their tireless work and cooperation.

Financial support. This research has been supported by the National Key Research and Development Program of China (grant no. 2017YFC1501702), the National Natural Science Foundation of China (grant nos. 41675141 and 41975174), and the BNU Interdisciplinary Research Foundation for the First-Year Doctoral Candidates (grant no. BNUXKJC2126).

Review statement. This paper was edited by Tuukka Petäjä and reviewed by two anonymous referees. 


\section{References}

Badger, C. L., George, I., Griffiths, P. T., Braban, C. F., Cox, R. A., and Abbatt, J. P. D.: Phase transitions and hygroscopic growth of aerosol particles containing humic acid and mixtures of humic acid and ammonium sulphate, Atmos. Chem. Phys., 6, 755-768, https://doi.org/10.5194/acp-6-755-2006, 2006.

Baklanov, A., Molina, L. T., and Gauss, M.: Megacities, air quality and climate, Atmos. Environ., 126, 235-249, https://doi.org/10.1016/j.atmosenv.2015.11.059, 2016.

Bidleman, T. F.: Atmospheric processes, Environ. Sci. Technol., 22, 361-367, https://doi.org/10.1021/es00169a002, 1988.

Bi, X., Dai, S., Zhang, G., Qiu, N., Li, M., Wang, X., Chen, D., Peng, P. a., Sheng, G., Fu, J., and Zhou, Z.: Real-time and singleparticle volatility of elemental carbon-containing particles in the urban area of Pearl River Delta region, China, Atmos. Environ., 118, 194-202, https://doi.org/10.1016/j.atmosenv.2015.08.012, 2015.

Brooks, B. J., Smith, M. H., Hill, M. K., and O'Dowd, C. D.: Size-differentiated volatility analysis of internally mixed laboratory-generated aerosol, J. Aerosol Sci., 33, 555-579, https://doi.org/10.1016/S0021-8502(01)00192-6, 2002.

Cai, M., Tan, H., Chan, C. K., Mochida, M., Hatakeyama, S., Kondo, Y., Schurman, M. I., Xu, H., Li, F., Shimada, K., Li, L., Deng, Y., Yai, H., Matsuki, A., Qin, Y., and Zhao, J.: Comparison of Aerosol Hygroscopcity, Volatility, and Chemical Composition between a Suburban Site in the Pearl River Delta Region and a Marine Site in Okinawa, Aerosol Air Qual. Res., 17, 3194-3208, https://doi.org/10.4209/aaqr.2017.01.0020, 2017.

Cappa, C. D. and Jimenez, J. L.: Quantitative estimates of the volatility of ambient organic aerosol, Atmos. Chem. Phys., 10, 5409-5424, https://doi.org/10.5194/acp-10-5409-2010, 2010.

Cappa, C. D., Onasch, T. B., Massoli, P., Worsnop, D. R., Bates, T. S., Cross, E. S., Davidovits, P., Hakala, J., Hayden, K. L., Jobson, B. T., Kolesar, K. R., Lack, D. A., Lerner, B. M., Li, S.-M., Mellon, D., Nuaaman, I., Olfert, J. S., Petäjä, T., Quinn, P. K., Song, C., Subramanian, R., Williams, E. J., and Zaveri, R. A.: Radiative Absorption Enhancements Due to the Mixing State of Atmospheric Black Carbon, Science, 337, 1078, https://doi.org/10.1126/science.1223447, 2012.

Chen, L., Zhang, F., Yan, P., Wang, X., Sun, L., Li, Y., Zhang, X., Sun, Y., and Li, Z.: The large proportion of black carbon (BC)-containing aerosols in the urban atmosphere, Environ. Pollut., 263, 114507, https://doi.org/10.1016/j.envpol.2020.114507, 2020.

Chen, S.-C., Tsai, C.-J., Huang, C.-Y., Chen, H.-D., Chen, S.-J., Lin, C.-C., Tsai, J.-H., Chou, C. C. K., Lung, S. C. C., Huang, W.-R., Roam, G.-D., Wu, W.-Y., Smolik, J., and Dzumbova, L.: Chemical Mass Closure and Chemical Characteristics of Ambient Ultrafine Particles and other PM Fractions, Aerosol Sci. Tech., 44, 713-723, https://doi.org/10.1080/02786826.2010.486385, 2010.

Cheng, Y. F., Berghof, M., Garland, R. M., Wiedensohler, A., Wehner, B., Müller, T., Su, H., Zhang, Y. H., Achtert, P., Nowak, A., Pöschl, U., Zhu, T., Hu, M., and Zeng, L. M.: Influence of soot mixing state on aerosol light absorption and single scattering albedo during air mass aging at a polluted regional site in northeastern China, J. Geophys. Res.-Atmos., 114, D00G10, https://doi.org/10.1029/2008jd010883, 2009.
Cheng, Y. F., Su, H., Rose, D., Gunthe, S. S., Berghof, M., Wehner, B., Achtert, P., Nowak, A., Takegawa, N., Kondo, Y., Shiraiwa, M., Gong, Y. G., Shao, M., Hu, M., Zhu, T., Zhang, Y. H., Carmichael, G. R., Wiedensohler, A., Andreae, M. O., and Pöschl, U.: Size-resolved measurement of the mixing state of soot in the megacity Beijing, China: diurnal cycle, aging and parameterization, Atmos. Chem. Phys., 12, 4477-4491, https://doi.org/10.5194/acp-12-4477-2012, 2012.

Cheung, H. H. Y., Tan, H., Xu, H., Li, F., Wu, C., Yu, J. Z., and Chan, C. K.: Measurements of non-volatile aerosols with a VTDMA and their correlations with carbonaceous aerosols in Guangzhou, China, Atmos. Chem. Phys., 16, 8431-8446, https://doi.org/10.5194/acp-16-8431-2016, 2016.

Dzubay, T. G., Stevens, R. K., Lewis, C. W., Hern, D. H., Courtney, W. J., Tesch, J. W., and Mason, M. A.: Visibility and aerosol composition in Houston, Texas, Environ. Sci. Technol., 16, 514 525, https://doi.org/10.1021/es00102a017, 1982.

Ehn, M., Petäjä, T., Birmili, W., Junninen, H., Aalto, P., and Kulmala, M.: Non-volatile residuals of newly formed atmospheric particles in the boreal forest, Atmos. Chem. Phys., 7, 677-684, https://doi.org/10.5194/acp-7-677-2007, 2007.

Frey, A., Rose, D., Wehner, B., Müller, T., Cheng, Y., Wiedensohler, A., and Virkkula, A.: Application of the Volatility-TDMA Technique to Determine the Number Size Distribution and Mass Concentration of Less Volatile Particles, Aerosol Sci. Technol., 42, 817-828, https://doi.org/10.1080/02786820802339595, 2008.

Gao, Y., Liu, X., Zhao, C., and Zhang, M.: Emission controls versus meteorological conditions in determining aerosol concentrations in Beijing during the 2008 Olympic Games, Atmos. Chem. Phys., 11, 12437-12451, https://doi.org/10.5194/acp-11-124372011, 2011.

Glasius, M. and Goldstein, A. H.: Recent Discoveries and Future Challenges in Atmospheric Organic Chemistry, Environ. Sci. Technol., 50, 2754-2764, https://doi.org/10.1021/acs.est.5b05105, 2016.

Grieshop, A. P., Lipsky, E. M., Pekney, N. J., Takahama, S., and Robinson, A. L.: Fine particle emission factors from vehicles in a highway tunnel: Effects of fleet composition and season, Atmos. Environ., 40, 287-298, https://doi.org/10.1016/j.atmosenv.2006.03.064, 2006.

Gysel, M., McFiggans, G. B., and Coe, H.: Inversion of tandem differential mobility analyser (TDMA) measurements, J. Aerosol Sci., 40, 134-151, https://doi.org/10.1016/j.jaerosci.2008.07.013, 2009.

Hakala, J., Mikkilä, J., Hong, J., Ehn, M., and Petäjä, T.: VH-TDMA: A description and verification of an instrument to measure aerosol particle hygroscopicity and volatility, Aerosol Sci. Technol., 51, 97-107, https://doi.org/10.1080/02786826.2016.1255712, 2017.

Häkkinen, S. A. K., Äijälä, M., Lehtipalo, K., Junninen, H., Backman, J., Virkkula, A., Nieminen, T., Vestenius, M., Hakola, H., Ehn, M., Worsnop, D. R., Kulmala, M., Petäjä, T., and Riipinen, I.: Long-term volatility measurements of submicron atmospheric aerosol in Hyytiälä, Finland, Atmos. Chem. Phys., 12, 1077110786, https://doi.org/10.5194/acp-12-10771-2012, 2012.

Huffman, J. A., Docherty, K. S., Aiken, A. C., Cubison, M. J., U1brich, I. M., DeCarlo, P. F., Sueper, D., Jayne, J. T., Worsnop, D. R., Ziemann, P. J., and Jimenez, J. L.: Chemically-resolved aerosol volatility measurements from two megacity field studies, 
Atmos. Chem. Phys., 9, 7161-7182, https://doi.org/10.5194/acp9-7161-2009, 2009.

Jacobson, M. Z.: Strong radiative heating due to the mixing state of black carbon in atmospheric aerosols, Nature, 409, 695-697, https://doi.org/10.1038/35055518, 2001.

Jiang, S., Ye, X., Wang, R., Tao, Y., Ma, Z., Yang, X., and Chen, J.: Measurements of nonvolatile size distribution and its link to traffic soot in urban Shanghai, Sci. Total Environ., 615, 452-461, https://doi.org/10.1016/j.scitotenv.2017.09.176, 2018.

Kuhn, T., Krudysz, M., Zhu, Y., Fine, P. M., Hinds, W. C., Froines, J., and Sioutas, C.: Volatility of indoor and outdoor ultrafine particulate matter near a freeway, J. Aerosol Sci., 36, 291-302, https://doi.org/10.1016/j.jaerosci.2004.09.006, 2005.

Lack, D. A. and Cappa, C. D.: Impact of brown and clear carbon on light absorption enhancement, single scatter albedo and absorption wavelength dependence of black carbon, Atmos. Chem. Phys., 10, 4207-4220, https://doi.org/10.5194/acp10-4207-2010, 2010.

Levy, M. E., Zhang, R., Zheng, J., Tan, H., Wang, Y., Molina, L. T., Takahama, S., Russell, L. M., and Li, G.: Measurements of submicron aerosols at the California-Mexico border during the Cal-Mex 2010 field campaign, Atmos. Environ., 88, 308-319, https://doi.org/10.1016/j.atmosenv.2013.08.062, 2014.

Liu, D., Joshi, R., Wang, J., Yu, C., Allan, J. D., Coe, H., Flynn, M. J., Xie, C., Lee, J., Squires, F., Kotthaus, S., Grimmond, S., Ge, X., Sun, Y., and Fu, P.: Contrasting physical properties of black carbon in urban Beijing between winter and summer, Atmos. Chem. Phys., 19, 6749-6769, https://doi.org/10.5194/acp19-6749-2019, 2019.

Meyer, M. B., Patashnick, H., Ambs, J. L., and Rupprecht, E.: Development of a sample equilibration system for the TEOM continuous PM monitor, J. Air Waste Manage., 50, 1345-1349, https://doi.org/10.1080/10473289.2000.10464180, 2000.

Moffet, R. C. and Prather, K. A.: In-situ measurements of the mixing state and optical properties of soot with implications for radiative forcing estimates, P. Natl. Acad. Sci. USA, 106, 11872, https://doi.org/10.1073/pnas.0900040106, 2009.

Nordmann, S., Cheng, Y. F., Carmichael, G. R., Yu, M., Denier van der Gon, H. A. C., Zhang, Q., Saide, P. E., Pöschl, U., Su, H., Birmili, W., and Wiedensohler, A.: Atmospheric black carbon and warming effects influenced by the source and absorption enhancement in central Europe, Atmos. Chem. Phys., 14, 1268312699, https://doi.org/10.5194/acp-14-12683-2014, 2014.

Park, K., Kim, J.-S., and Miller, A. L.: A study on effects of size and structure on hygroscopicity of nanoparticles using a tandem differential mobility analyzer and TEM, J. Nanopart. Res., 11, 175-183, https://doi.org/10.1007/s11051-008-9462-4, 2009.

Philippin, S., Wiedensohler, A., and Stratmann, F.: Measurements of non-volatile fractions of pollution aerosols with an eight-tube volatility tandem differential mobility analyzer (VTDMA-8), J. Aerosol Sci., 35, 185-203, https://doi.org/10.1016/j.jaerosci.2003.07.004, 2004.

Poulain, L., Birmili, W., Canonaco, F., Crippa, M., Wu, Z. J., Nordmann, S., Spindler, G., Prévôt, A. S. H., Wiedensohler, A., and Herrmann, H.: Chemical mass balance of $300{ }^{\circ} \mathrm{C}$ non-volatile particles at the tropospheric research site Melpitz, Germany, Atmos. Chem. Phys., 14, 10145-10162, https://doi.org/10.5194/acp-14-10145-2014, 2014.
Pöschl, U.: Atmospheric Aerosols: Composition, Transformation, Climate and Health Effects, Angew. Chem. Int. Edit., 44, 75207540, https://doi.org/10.1002/anie.200501122, 2005.

Riipinen, I., Yli-Juuti, T., Pierce, J. R., Petäjä, T., Worsnop, D. R., Kulmala, M., and Donahue, N. M.: The contribution of organics to atmospheric nanoparticle growth, Nat. Geosci., 5, 453-458, https://doi.org/10.1038/ngeo1499, 2012.

Rose, D., Wehner, B., Ketzel, M., Engler, C., Voigtländer, J., Tuch, T., and Wiedensohler, A.: Atmospheric number size distributions of soot particles and estimation of emission factors, Atmos. Chem. Phys., 6, 1021-1031, https://doi.org/10.5194/acp-6-10212006, 2006.

Saha, P. K., Khlystov, A., and Grieshop, A. P.: Downwind evolution of the volatility and mixing state of near-road aerosols near a US interstate highway, Atmos. Chem. Phys., 18, 2139-2154, https://doi.org/10.5194/acp-18-2139-2018, 2018.

Sakurai, H., Park, K., McMurry, P. H., Zarling, D. D., Kittelson, D. B., and Ziemann, P. J.: Size-Dependent Mixing Characteristics of Volatile and Nonvolatile Components in Diesel Exhaust Aerosols, Environ. Sci. Technol., 37, 5487-5495, https://doi.org/10.1021/es034362t, 2003.

Sakurai, H., Fink, M. A., McMurry, P. H., Mauldin, L., Moore, K. F., Smith, J. N., and Eisele, F. L.: Hygroscopicity and volatility of 4-10 nm particles during summertime atmospheric nucleation events in urban Atlanta, J. Geophys. Res.-Atmos., 110, D22S04, https://doi.org/10.1029/2005JD005918, 2005.

Sun, Y., Chen, C., Zhang, Y., Xu, W., Zhou, L., Cheng, X., Zheng, H., Ji, D., Li, J., Tang, X., Fu, P., and Wang, Z.: Rapid formation and evolution of an extreme haze episode in Northern China during winter 2015, Sci. Rep., 6, 27151, https://doi.org/10.1038/srep27151, 2016a.

Sun, Y., Wang, Z., Wild, O., Xu, W., Chen, C., Fu, P., Du, W., Zhou, L., Zhang, Q., Han, T., Wang, Q., Pan, X., Zheng, H., Li, J., Guo, X., Liu, J., and Worsnop, D. R.: "APEC Blue": Secondary Aerosol Reductions from Emission Controls in Beijing, Sci. Rep., 6, 20668, https://doi.org/10.1038/srep20668, 2016 b.

Tan, H., Xu, H., Wan, Q., Li, F., Deng, X., Chan, P. W., Xia, D., and Yin, Y.: Design and Application of an Unattended Multifunctional H-TDMA System, J. Atmos. Ocean. Tech., 30, 11361148, https://doi.org/10.1175/jtech-d-12-00129.1, 2013.

Villani, P., Picard, D., Marchand, N., and Laj, P.: Design and Validation of a 6-Volatility Tandem Differential Mobility Analyzer (VTDMA), Aerosol Sci. Tech., 41, 898-906, https://doi.org/10.1080/02786820701534593, 2007.

Wang, L., Liu, Z., Sun, Y., Ji, D., and Wang, Y.: Long-range transport and regional sources of $\mathrm{PM}_{2.5}$ in Beijing based on longterm observations from 2005 to 2010, Atmos. Res., 157, 37-48, https://doi.org/10.1016/j.atmosres.2014.12.003, 2015.

Wang, T., Nie, W., Gao, J., Xue, L. K., Gao, X. M., Wang, X. F., Qiu, J., Poon, C. N., Meinardi, S., Blake, D., Wang, S. L., Ding, A. J., Chai, F. H., Zhang, Q. Z., and Wang, W. X.: Air quality during the 2008 Beijing Olympics: secondary pollutants and regional impact, Atmos. Chem. Phys., 10, 7603-7615, https://doi.org/10.5194/acp-10-7603-2010, 2010.

Wang, X., Shen, X. J., Sun, J. Y., Zhang, X. Y., Wang, Y. Q., Zhang, Y. M., Wang, P., Xia, C., Qi, X. F. and Zhong, J. T.: Size-resolved hygroscopic behavior of atmospheric aerosols during heavy aerosol pollution episodes in 
Beijing in December 2016, Atmos. Environ., 194, 188-197, https://doi.org/10.1016/j.atmosenv.2018.09.041, 2018.

Wang, Y., Zhang, F., Li, Z., Tan, H., Xu, H., Ren, J., Zhao, J., $\mathrm{Du}$, W., and Sun, Y.: Enhanced hydrophobicity and volatility of submicron aerosols under severe emission control conditions in Beijing, Atmos. Chem. Phys., 17, 5239-5251, https://doi.org/10.5194/acp-17-5239-2017, 2017.

Wang, Y. Q., Zhang, X. Y., and Draxler, R. R.: TrajStat: GISbased software that uses various trajectory statistical analysis methods to identify potential sources from long-term air pollution measurement data, Environ. Model. Softw., 24, 938-939, https://doi.org/10.1016/j.envsoft.2009.01.004, 2009.

Wang, Z., Birmili, W., Hamed, A., Wehner, B., Spindler, G., Pei, X., Wu, Z., Cheng, Y., Su, H., and Wiedensohler, A.: Contributions of volatile and nonvolatile compounds (at $300^{\circ} \mathrm{C}$ ) to condensational growth of atmospheric nanoparticles: An assessment based on 8.5 years of observations at the Central Europe background site Melpitz, J. Geophys. Res.-Atmos., 122, 485-497, https://doi.org/10.1002/2016JD025581, 2017.

Wehner, B., Philippin, S., Wiedensohler, A., Scheer, V., and Vogt, R.: Variability of non-volatile fractions of atmospheric aerosol particles with traffic influence, Atmos. Environ., 38, 6081-6090, https://doi.org/10.1016/j.atmosenv.2004.08.015, 2004.

Wehner, B., Berghof, M., Cheng, Y. F., Achtert, P., Birmili, W., Nowak, A., Wiedensohler, A., Garland, R. M., Pöschl, U., Hu, M., and Zhu, T.: Mixing state of nonvolatile aerosol particle fractions and comparison with light absorption in the polluted Beijing region, J. Geophys. Res.-Atmos., 122, 485-497, https://doi.org/10.1029/2008jd010923, 2009.

Wu, H., Li, Z., Li, H., Luo, K., Wang, Y., Yan, P., Hu, F., Zhang, F., Sun, Y., Shang, D., Liang, C., Zhang, D., Wei, J., Wu, T., Jin, X., Fan, X., Cribb, M., Fischer, M. L., Kulmala, M., and Petäjä, T.: The impact of the atmospheric turbulence-development tendency on new particle formation: a common finding on three continents, Nat. Sci. Rev., 8, nwaa157, https://doi.org/10.1093/nsr/nwaa157, 2020.

Wu, Z. J., Ma, N., Größ, J., Kecorius, S., Lu, K. D., Shang, D. J., Wang, Y., Wu, Y. S., Zeng, L. M., Hu, M., Wiedensohler, A., and Zhang, Y. H.: Thermodynamic properties of nanoparticles during new particle formation events in the atmosphere of North China Plain, Atmos. Res., 188, 55-63, https://doi.org/10.1016/j.atmosres.2017.01.007, 2017.
Yeung, M. C., Lee, B. P., Li, Y. J., and Chan, C. K.: Simultaneous HTDMA and HR-ToF-AMS measurements at the HKUST Supersite in Hong Kong in 2011, J. Geophys. Res.-Atmos., 119, 9864-9883, https://doi.org/10.1002/2013JD021146, 2014.

Xu, L., Williams, L. R., Young, D. E., Allan, J. D., Coe, H., Massoli, P., Fortner, E., Chhabra, P., Herndon, S., Brooks, W. A., Jayne, J. T., Worsnop, D. R., Aiken, A. C., Liu, S., Gorkowski, K., Dubey, M. K., Fleming, Z. L., Visser, S., Prévôt, A. S. H., and Ng, N. L.: Wintertime aerosol chemical composition, volatility, and spatial variability in the greater London area, Atmos. Chem. Phys., 16, 1139-1160, https://doi.org/10.5194/acp-16-1139-2016, 2016.

Zhang, F., Wang, Y., Peng, J., Chen, L., Sun, Y., Duan, L., Ge, X., Li, Y., Zhao, J., Liu, C., Zhang, X., Zhang, G., Pan, Y., Wang, Y., Zhang, A. L., Ji, Y., Wang, G., Hu, M., Molina, M. J., and Zhang, R.: An unexpected catalyst dominates formation and radiative forcing of regional haze, P. Natl. Acad. Sci. USA, 117, 3960, https://doi.org/10.1073/pnas.1919343117, 2020.

Zhang, S. L., Ma, N., Kecorius, S., Wang, P. C., Hu, M., Wang, Z. B., Größ, J., Wu, Z. J., and Wiedensohler, A.: Mixing state of atmospheric particles over the North China Plain, Atmos. Environ., 125, 152-164, https://doi.org/10.1016/j.atmosenv.2015.10.053, 2016.

Zhang, Y., Zhang, Q., Cheng, Y., Su, H., Kecorius, S., Wang, Z., Wu, Z., Hu, M., Zhu, T., Wiedensohler, A., and He, K.: Measuring the morphology and density of internally mixed black carbon with SP2 and VTDMA: new insight into the absorption enhancement of black carbon in the atmosphere, Atmos. Meas. Tech., 9, 1833-1843, https://doi.org/10.5194/amt-9-1833-2016, 2016.

Zhang, Y., Su, H., Kecorius, S., Wang, Z., Hu, M., Zhu, T., He, K., Wiedensohler, A., Zhang, Q., and Cheng, Y.: Mixing State of Refractory Black Carbon of the North China Plain Regional Aerosol Combining a Single Particle Soot Photometer and a Volatility Tandem Differential Mobility Analyzer, Atmos. Chem. Phys. Discuss. [preprint], https://doi.org/10.5194/acp-2017-222, 2017.

Zhang, Y., Zhang, Q., Cheng, Y., Su, H., Li, H., Li, M., Zhang, X., Ding, A., and He, K.: Amplification of light absorption of black carbon associated with air pollution, Atmos. Chem. Phys., 18, 9879-9896, https://doi.org/10.5194/acp-18-9879-2018, 2018. 